\title{
ARTÍCULO
}

\section{In memoriam, Mario Ruiz (1967-2018)}

\author{
Javier de Lucas \\ Senador de la XIII Legislatura \\ Instituto de Derechos Humanos \\ Universitat de València
}

Fecha de recepción 01/06/2019 | De publicación: 27/06/2019

El profesor Mario Ruiz, director del Anuario de Filosofia del Derecho, revista oficial de la Sociedad Española de Filosofía Jurídica y Política, falleció el 29 de abril de 2018 en Valencia. Agradezco a la profesora Maria José Añón, directora de los Cuadernos Electrónicos de Filosofía del Derecho, una magnífica revista a cuya consolidación tanto contribuyó Mario Ruiz, la iniciativa de este monográfico que recoge algunos de los homenajes organizados en su memoria y que me permite expresar el mío propio.

Parece lógico destacar que una comunidad científica existe en buena medida si cuenta con órganos de difusión, intercambio y debate entre quienes forman parte de ella, es decir, revistas científicas propias. Para los iusfilósofos españoles (y no sólo españoles), entre esas revistas ocupa un lugar estacado el Anuario de Filosofía del Derecho, que forma parte de la colección de Anuarios editados por el Ministerio de justicia, en este caso con la Sociedad Española de Filosofía Jurídica y Política. Pues bien, parece incontestable que buena parte de la contribución de Mario Ruiz a los estudios sobre el pensamiento filosófico jurídico y político español se vinculan, ciertamente, a su trabajo en esta revista, de la que llegó a ser director. Ya desde 2001 había sido miembro de su Consejo de Redacción y luego secretario (2005), cargo que ejerció hasta que sucedió a la profesora María José Añón en la dirección, en el año 2015. Por tanto, la historia del Anuario casi en sus últimos veinte años, no se puede entender sin el trabajo de Mario Ruiz, que le dedicó lo mejor de su esfuerzo.

Mario Ruiz nació en Montesa (Valencia), el 27 de marzo de 1967. Tras licenciarse en Derecho en la Universidad de Valencia en 1990, cursó el programa de Doctorado interuniversitario "Racionalidad y Derecho", un proyecto que tuve el privilegio de impulsar desde el Departamento de Filosofía del Derecho de la Universitat de València, con el apoyo del Centro de Estudios 
Constitucionales que dirigía el profesor Francisco Laporta, la Universidad Internacional Menéndez Pelayo y los Departamentos de Filosofía del Derecho de las Universidades de Alicante, Autónoma de Madrid, Castilla La Mancha, Pompeu Fabra y Sevilla. Fue una experiencia en muchos sentidos excepcional, que marcó a una generación de jóvenes investigadores y creó fuertes vínculos que aún hoy permanecen entre la mayoría de ellos.

La primera contribución de Mario Ruiz que debemos destacar fue su monografía de1997, Enrique Tierno Galván. Aproximación a su vida, obra y pensamiento (Universidad Carlos III-ed. Dykinson, Madrid), que tuvo origen en su tesis doctoral, presentada en 1995 y que tuve el honor de dirigir. A su vez, esa tesis tuvo su origen en una indicación de Elías Díaz, que le propuso a Mario investigar sobre las dimensiones filosófico-jurídicas y políticas en la obra del viejo profesor. Elías le prestó generosamente una ayuda decisiva y, sin figurar como director de la tesis, ejerció como tal. Le acogió con frecuencia en la Universidad Autónoma y le puso en contacto con el autor de una tesis anterior sobre Tierno, más centrada en el análisis filosófico, también dirigida por Elías. Me refiero al profesor Jorge Novella, que se convirtió en un firme apoyo para el trabajo de Mario, a quien ayudó también con una generosidad que no puedo menos que agradecer. Ya por entonces, tras unos cursos como profesor en el Departamento de Valencia, llevaba tres años incorporado a la Universitat Rovira i Virgili, gracias a la confianza que le otorgaron los profesores Jaume Vernet i Llobet y Antoni Pigrau, que fueron siempre dos de sus mejores y constantes amigos de esa Universidad de Tarragona, en la que ha dejado no sólo muchos amigos sino también discípulos excelentes como Angels Galiana, Victor Merino y Juan Ramón Fallada. En la URV obtuvo por concurso la plaza de profesor titular de Filosofía del Derecho en 1997. Y en esa su Universidad, desempeñó los cargos de Vicedecano de ordenación académica y Jefe de Estudios de le Facultad de Derecho (1997-2001), Delegado del Rector para la mejora de la calidad docente y Secretario General de la Universidad (2014-2016). En el año 2013 -el mismo en que le operaron de un doble transplante de páncreas y riñón- fue acreditado a catedrático de Universidad por la ANECA y desde ese año tenía también la condición de investigador con grado de recerca avançada por la AQU, la Agencia de Evaluación universitaria de la Generalitat de Catalunya. Se le habían reconocido asimismo 4 tramos de docencia y 3 tramos de investigación por la CNEAI y los tramos adicionales por parte de la AQU. Añadiré que dirigió cuatro tesis doctorales, las de Angels Galiana, (con J de Lucas como codirector), María Olivé (con G.Gilberti como codirector), Maria Fernanda López Portillo y Juan Ramón Fallada, que obtuvieron la máxima calificación. Creo que ha de 
constar asimismo su trabajo al frente de la revista electrónica Cuadernos Electrónicos de Filosofía del Derecho, que fue iniciativa de quien suscribe siendo aún director del Anuario, en 1998 y que editamos desde la Universitat de València. Desde 2015 la dirigió Mario Ruiz y consiguió para ella el sello de la FECYT en 2016.

Cinco campos centraron, a mi juicio, su interés en el ámbito de la investigación: problemas de racionalidad y argumentación jurídicas, algunos temas conceptuales y metodológicos básicos de Teoría del Derecho, cuestiones de reconocimiento y garantía de los derechos de quienes pertenecen a grupos vulnerables (en especial, aunque no sólo, de los inmigrantes), con particular atención a la protección contra la discriminación, y los aspectos filosófico-jurídicos de la justicia ambiental, pues Mario fue uno de los impulsores del grupo de investigación multidisciplinar sobre la materia en la URV que cristalizó en un buen número de publicaciones y en diferentes iniciativas docentes de especialización y posgrado. A ellos se añade el de la docencia del Derecho a través del cine, a la que dedicó una gran parte de su trabajo y un buen número de publicaciones que considero de obligada referencia en ese campo.

En torno a esos ejes se pueden distribuir sus publicaciones e intervenciones en jornadas, congresos y seminarios, buena parte de los cuales contribuyó a organizar. Así, sus cuatro libros: el primero tuvo su origen en su ya mencionada tesis doctoral Enrique Tierno Galván. Aproximación a su vida, obra y pensamiento (1997). Tras él, destacaría otros dos en los que se reflejaba la influencia del programa de doctorado, que marcó uno de los intereses prioritarios en su investigación ya mencionados, los problemas, conflictos y déficit de la racionalidad jurídica: Sistemas jurídicos y conflictos normativos, (2002) y La construcción coherente del Derecho, (2009). El cuarto fue precisamente el libro con el que inauguramos hace 15 años, en 2003, la colección Cine y Derecho (editorial Tirant lo Blanch). Me refiero a El verdugo: un retrato satírico del asesino legal. Todavía recuerdo (y algunos también lo atesorarán en la memoria, seguro) el divertido asombro que le provocó a Luis García Berlanga ese libro de Mario y cómo discutieron sobre él, en Santander, donde coincidimos -en dos cursos distintos- con el gran maestro valenciano. Una conversación en la que Mario se atrevía a precisar o discutir con él sobre este o aquel detalle de su película.

A nadie extrañará que dedique un poco más de atención al papel de Mario Ruiz en esa iniciativa, que forma parte de un proyecto de más amplio alcance sobre la docencia del Derecho a 
través del cine y que compartimos con compañeros de otras Universidades españolas y extranjeras. Cuando inicié ese proyecto editorial, Mario me acompañó sin dudarlo, y hasta ayer mismo supo coordinar con generosidad todo el trabajo, suplió mis ausencias y multiplicó las iniciativas y propuestas que condujeron a establecer dos series y a superar el medio centenar de títulos. Pero también impulsó y colaboró generosamente en las iniciativas de docencia e investigación relacionadas con cine, literatura y Derecho que desarrollaron colegas de otras Universidades: el grupo de la Universidad de Oviedo, los grupos de la Carlos III, Santander, Barcelona, Pompeu Fabra, Zaragoza, Sevilla, Málaga, Vigo/Ourense, la UNED... Fue este un proyecto que también contribuyó, creo, a estrechar lazos de docencia, investigación y, sobre todo, de amistad entre Mario y todos los que teníamos la oportunidad de pasar horas discutiendo con él -muchas veces con Isabel, su mujer, la persona que la suerte puso en su camino en 2008 para fortuna de Mario- sobre problemas jurídicos y cinematográficos, sin que dejara nunca de causarnos admiración su conocimiento $\mathrm{y}$, por qué no decirlo, su gusto por provocar y desconcertar a los interlocutores con ingeniosas argumentaciones -a veces al límite de lo verosímilsobre ignotas y heterodoxas novedades o curiosidades cinematográficas que podían servir para ilustrar este o aquel problema de doctrina o jurisprudencia. La profesora Cristina García Pascual, que compartió tantas horas de trabajo y también de cine y conversación con él lo sabe muy bien. Como lo hizo su buen amigo y compañero José García Añón. Otros lamentamos ahora no haber sabido acompañarle como merecía.

Nunca le abandonó esa voluntad de provocación inteligente que, tras una capa aparente de frivolidad que él mismo gustaba de cultivar, enseguida dejaba advertir una capacidad para tratar de modo tan novedoso como en profundidad problemas de trascendencia jurídica. No puedo, como es lógico, detallar todas las publicaciones e intervenciones en las que consiguió plasmarlo. Me limitaré a señalar como ejemplo un artículo que publicó en el año 2009 en el número 5 de la revista Teoría y Derecho, sobre un caso en el que se ponía en juego uno de esos ejes prioritarios de su investigación que he mencionado, el estudio de las manifestaciones de discriminación y del alcance del Derecho en la lucha por su eliminación. Me refiero a su bien conocido trabajo de 2009 "A propósito de lo digno y no discriminatorio: comentario al caso Wakenheim v. Francia sobre el "<lanzamiento del enano>”.

No despedimos a Mario Ruiz. Seguiremos dialogando con él, porque nos queda su obra y la memoria de tanto que con él hemos querido y compartido. 